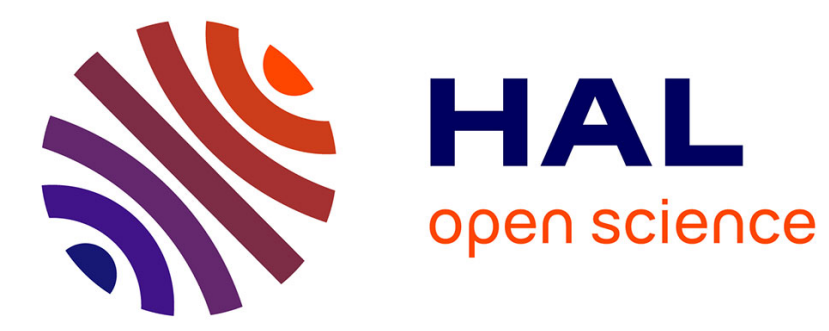

\title{
Thermodynamic Assessment of the Fe-Te System. Part I: Experimental study
}

\author{
C.-M. Arvhult, S. Poissonnet, D. Menut, S. Gossé, C. Guéneau
}

\section{To cite this version:}

C.-M. Arvhult, S. Poissonnet, D. Menut, S. Gossé, C. Guéneau. Thermodynamic Assessment of the Fe-Te System. Part I: Experimental study. Journal of Alloys and Compounds, 2018, 773, pp.314-326. 10.1016/j.jallcom.2018.09.265 . cea-02339819

\section{HAL Id: cea-02339819 https://hal-cea.archives-ouvertes.fr/cea-02339819}

Submitted on 5 Nov 2019

HAL is a multi-disciplinary open access archive for the deposit and dissemination of scientific research documents, whether they are published or not. The documents may come from teaching and research institutions in France or abroad, or from public or private research centers.
L'archive ouverte pluridisciplinaire HAL, est destinée au dépôt et à la diffusion de documents scientifiques de niveau recherche, publiés ou non, émanant des établissements d'enseignement et de recherche français ou étrangers, des laboratoires publics ou privés. 


\title{
Thermodynamic Assessment of the Fe-Te System. Part I: Experimental study
}

C.-M. Arvhult ${ }^{\mathrm{a}}$, S. Poissonnet ${ }^{\mathrm{b}}$, D. Menut ${ }^{\mathrm{c}}$, S. Gosséd ${ }^{\mathrm{d}}$, C. Guéneau ${ }^{\mathrm{d}}$

${ }^{a}$ KTH Royal Institute of Technology, ITM, Dept. of Materials Science and Engineering, Unit of Structures. Brinellvägen 23, SE-100 44 Stockholm, Sweden

${ }^{b}$ Den-Service de Recherches de Métallurgie Physique (SRMP), CEA, Université Paris-Saclay, F-91191 Gif-sur-yvette, France

${ }^{c}$ Synchrotron SOLEIL, Division Experiences, Ligne MARS, L'Orme des Merisiers, Saint Aubin BP48, 91192 Gif-sur-Yvette, France

${ }^{d}$ Den-Service de Corrosion et du Comportement des Matériaux dans leur Environnement (SCCME), CEA, Université Paris-Saclay, F-91191 Gif-sur-Yvette, France

Corresponding author: arvhult@kth.se

\begin{abstract}
A thermodynamic description of the Fe-Te system needs to be developed in order to model internal corrosion by fission products in fuel pins of Generation IV nuclear reactors. In preparation for a thermodynamic assessment of the system, an experimental study has been performed in order to clarify some unknown or conflicting phase diagram data. New phase diagram data have been obtained using Differential Thermal Analysis and isothermal heat treatments followed by electron microscopy with EDS and WDS analysis. The DTA analysis revealed new phase boundary data, and confirmed a very steep Fe-rich liquidus, supporting the possibility of a liquid miscibility gap in the FeFeTe region. The analyses also confirmed the probable eutectoid reaction $\delta \rightarrow \beta+\delta^{\prime}$ at $523^{\circ} \mathrm{C}$. The invariant arrests of the unknown $\gamma$ phase were consistent with information available in literature, but the phase was not identified via XRD of samples at its postulated composition. However, metallography of the samples revealed an unexpected microstructure pertaining to the $\delta$ phase, which might be the $\gamma$ phase, and is discussed in this paper. The monoclinic space group $C 2 / \mathrm{m}$ is proposed for the $\delta$ phase based on XRD. The collected data will be used together with that available in literature to perform a thermodynamic Calphad assessment in a subsequent paper Part II: Thermodynamic modelling.
\end{abstract}

Keywords: "nuclear reactor materials", "thermal analysis", "scanning electron microscopy, SEM", "metallography", "X-ray diffraction", "phase transitions"

\section{Introduction}

Most commercial light water reactors (LWR) operate in a thermal neutron spectrum, with zirconium alloys as the fuel encapsulation (cladding). Among Generation IV nuclear reactors currently under development are the Sodium cooled Fast neutron Reactors (SFR), operating with a fast-neutron spectrum and a liquid sodium coolant. The MOX fuel (mixed oxide of uranium and plutonium) pellets are contained in stainless steel cladding. Post irradiation examination of MOX fuel pins from SFR reactors have revealed an internal corrosion process where some fission products initiate FuelCladding Chemical Interaction ( $\mathrm{FCCl}$ ) and Fission-Product induced Liquid Metal Embrittlement (FPLME) [1-3]. This corrosion is facilitated by the release and migration of these volatile fission 
products from the fuel, into the fuel pin gap, and cesium and tellurium are key elements in this process.

Thermodynamic studies of the effect of Cs and Te on stainless steel have concluded that the hyperstoichiometry of the oxide fuel during burnup results in a sufficiently high tellurium potential to enable corrosion [4-6]. Pulham and Richards [7-11] made experimental studies on the corrosion of $\mathrm{Cs}, \mathrm{Te}$ and $(\mathrm{Cs}, \mathrm{Te})$ mixtures with varying oxygen potential on the candidate cladding alloys Nimonic PE16, austenitic M316 and ferritic FV448 and DT2203Y05. They concluded that the corrosion process, including steel matrix attack and inter-granular corrosion, is sensitive to different Cs/Te ratios and oxygen potentials, which change the mode of corrosion. In most cases, transition metal tellurides and oxides were formed, deposited in scales composed mainly of $\mathrm{Cr}$ - $\mathrm{Cs}$ and $\mathrm{Cr}$-Te compounds at low oxygen potentials, and $\mathrm{Fe}-\mathrm{Te}, \mathrm{Cs}-\mathrm{Fe}-\mathrm{O}$ and $\mathrm{Cs}-\mathrm{Cr}-\mathrm{O}$ compounds at high potentials.

In order to predict whether or not this internal corrosion of the fuel pins during operation will be a life-limiting factor of the reactor, a corrosion model has to be implemented. As input data for that model, a thermodynamic database of the Fe-Cr-Ni-Cs-Te-O system must be developed. In order to assess such a complex system, all the binary, ternary and higher-order sub-systems need to be assessed.

This paper presents an experimental study of the Fe-Te phase diagram, to be included in the thermodynamic assessment presented in Part II: Thermodynamic modelling. Section 2 summarizes the state of the art of the Fe-Te system. Section 3 then describes the experimental methods used, followed by a discussion of the results of metallographic studies on annealed samples in section 4.1, and an analysis of heat curves from DTA in section 4.2. Finally, section 5 summarizes the main conclusions and gives suggestions for future work.

\section{State of the art on the Fe-Te system}

In their work, Grønvold et al. [12] characterized most known phases of the iron-tellurium system, i.e. the $\beta, \delta, \delta^{\prime}$ and $\epsilon$ phases. This was later completed with the discovery of another high-temperature phase, $\beta^{\prime}$, by Røst and Webjørnsen [13]. A number of researchers then published experimental phase diagrams and homogeneity ranges of the Fe-Te system [14-18]. Ipser et al. [19] observed inconsistencies between those diagrams, and revised the phase diagram based on isopiestic, Thermal Analysis (TA), Differential Thermal Analysis (DTA) and X-ray diffraction (XRD) measurements, as shown in Figure 1a. Chattopadhyay and Bharadwaj [20] reviewed the system and accepted the phase diagram by Ipser et al., adding a liquid miscibility gap suggested by Mann and Van Vlack [21] in their partial diagram shown in Figure 1b. Okamoto and Tanner [22] published a separate review, accepting a similar phase diagram including an austenite loop. 

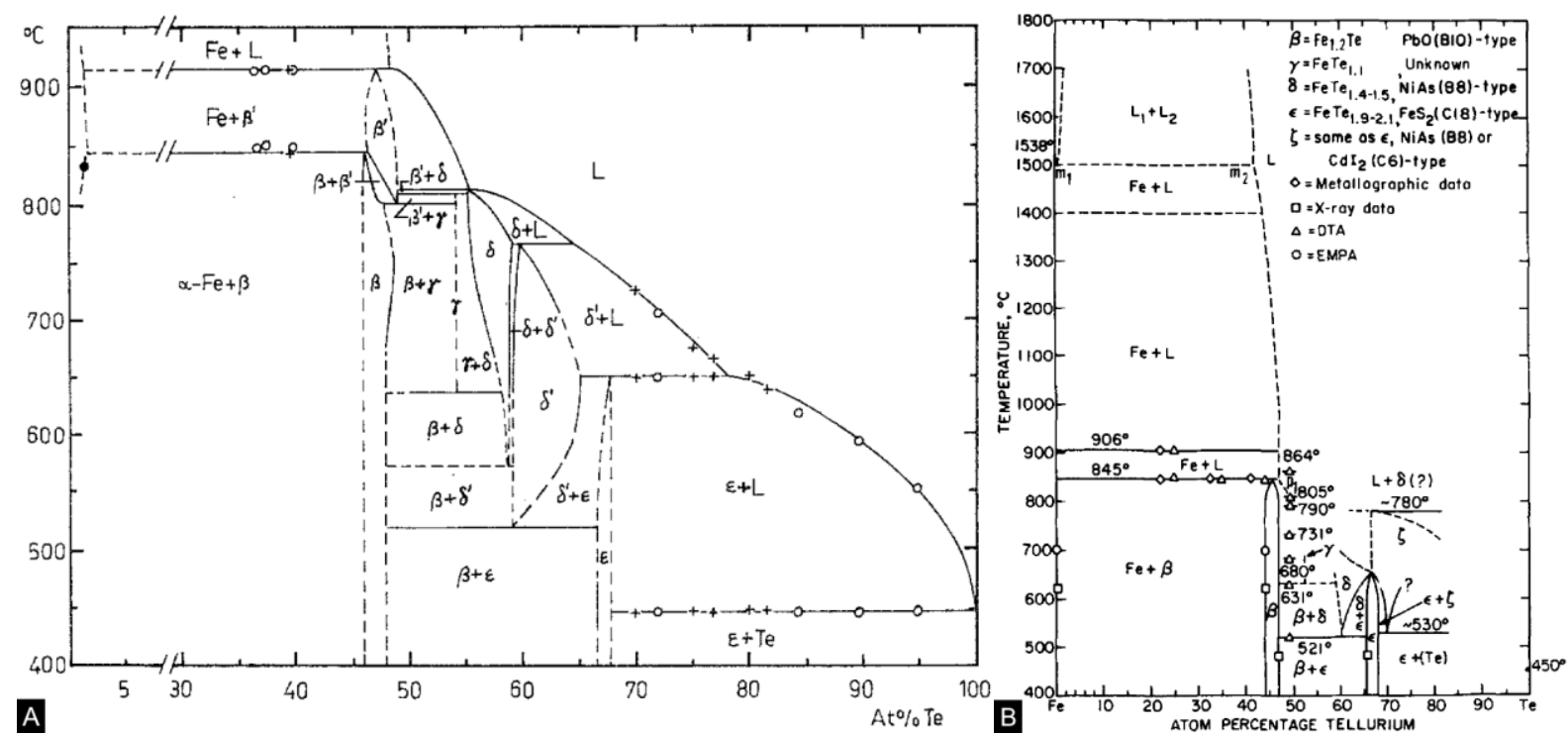

Figures 1a and 1b: Fe-Te phase diagrams by Ipser et al. [19] (1a) and Mann and Van Vlack [21] (1b).

Table 1 presents the available crystallographic data of the system, as well as their approximate chemical formulae. The designation of Greek letters by Grønvold et al. will be used throughout this text. Several XRD studies are available on the crystal structures of the $\beta, \delta$ and $\epsilon$ phases $[12,19,23-$ $25]$. As shown in Figure 1a, Ipser et al. proposed the existence of $\delta$ and $\delta^{\prime}$ single-phase regions with an intermediate two-phase region. The $\mathrm{Cdl}_{2}$-type ordering of the hexagonal $\delta^{\prime}$ phase was confirmed by Mössbauer and neutron diffraction studies $[26,27]$. While the monoclinic $\delta$ phase is related to the $\mathrm{NiAs}$ structure family, the exact space group remains unknown. In the $\mathrm{Ni}$-Te system, the Ni-rich $\delta$ phase is of the NiAs structure, experiencing a $2^{\text {nd }}$ order transition into the $\mathrm{Cdl}_{2}$-type with increased Te-content $[28,29]$. Modelling has supported the possibility of a $\delta \rightarrow \delta^{\prime}$ order-disorder transformation in the Fe-Te system, but it has not been experimentally confirmed [30].

The ordered nature of the $\beta$ phase has been confirmed by neutron diffraction studies as an intermediate state between the $\mathrm{Cu}_{2} \mathrm{Sb}$ and $\mathrm{PbO}$ type structures, with half of the tetrahedral sites filled with Fe atoms, and excess Fe in the octahedral sites [31,32]. The high-temperature $\beta^{\prime}$ phase was observed by Røst and Webjørnsen as similar to the $R \overline{3} m$ (160) $\mathrm{Fe}_{1.5} \mathrm{Ni}_{1.5} \mathrm{Te}_{2}$ phase found by Stevels [33], a ternary phase that was later re-characterized as $R 3 m$ (166) by Åkesson and Røst, known as $\mathrm{Fe}_{0.28} \mathrm{Ni}_{0.28} \mathrm{Te}_{0.44}[13,34]$. Only a few reflections were noted, with qualitative intensities, but all shared with the $\mathrm{Fe}_{0.28} \mathrm{Ni}_{0.28} \mathrm{Te}_{0.44}$ structure.

Reflections of a phase of unknown crystal structure were found between the $\beta$ and $\delta$ phase, called the $\gamma$ phase, believed to exist at 54.2 at\% Te (Figures 1) [12,19]. 
Table 1: Crystallographic data of Fe-Te phases. Lattice parameters available in literature is given for phases relevant to this work. It: low-temperature phase, ht: high-temperature phase, hp: high-pressure phase. *: Crystal structure not confirmed.

**: Suggested by Chevreton [35], without evidence; this work later finds that the phase may be of this space group, however not this prototype.

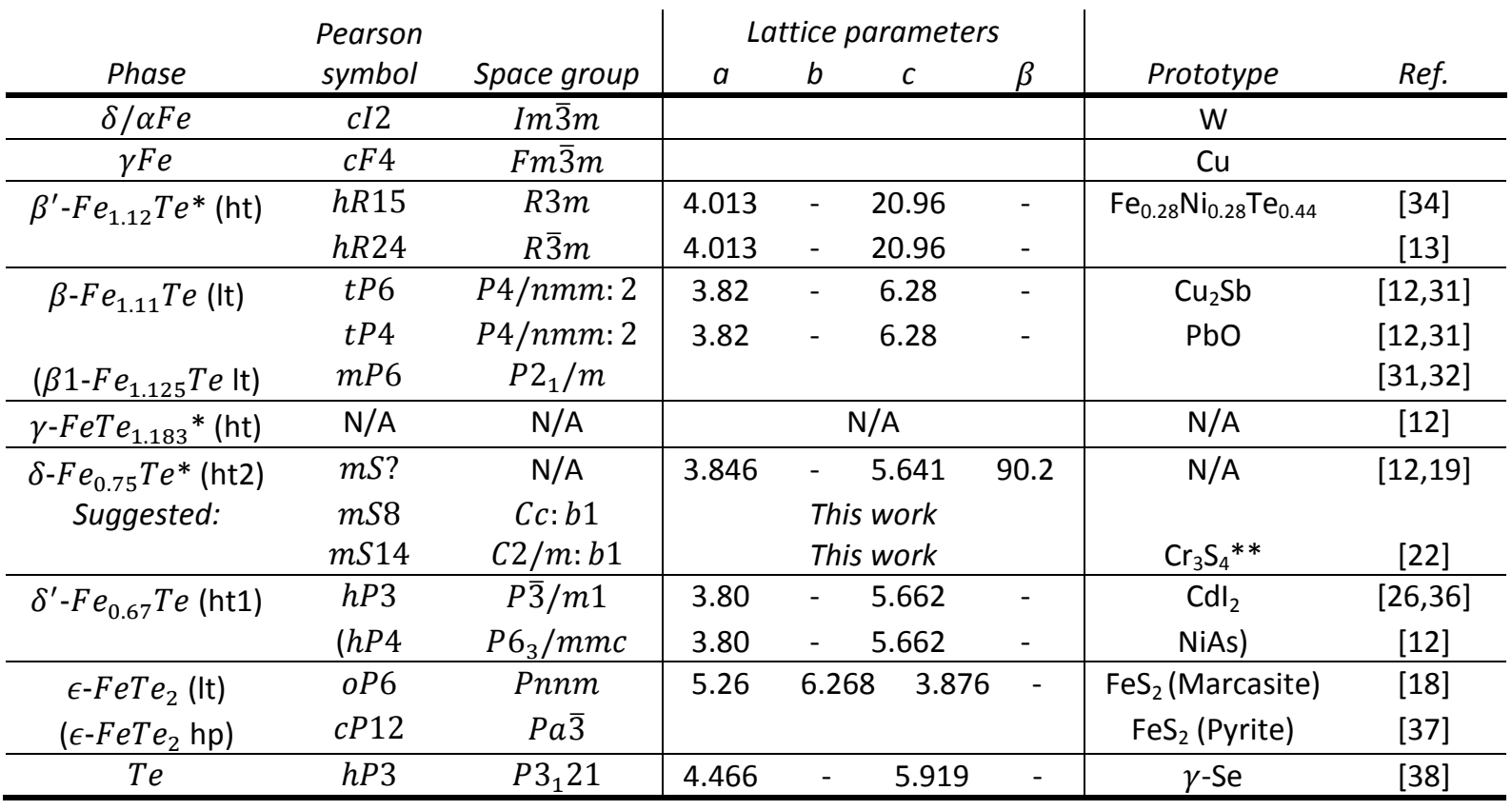

Although much work has been done to study the Fe-Te system, some questions remain that may significantly affect the thermodynamic modeling of the system. Mann and Van Vlack [21] suggested a liquid miscibility gap in the Fe-FeTe region (Figure 1b) which was accepted by Okamoto and Tanner [22], while no Fe-rich liquidus data nor activity data exist to support this. The Te-rich phase boundary of the $\epsilon$ phase remains largely uncertain, as well as the $\delta \rightarrow \delta^{\prime}+\beta$ transformation and the solvus lines of the $\delta$ and $\delta^{\prime}$ phases.

In the present work, we performed isothermal heat treatments with metallographic studies and DTA in order to determine these unknown or uncertain phase boundaries of the Fe-Te system, as well as gain more insight into the nature of the $\gamma$ and $\delta$ phases. An explanation of the experimental methods employed follows in section 3 .

\section{Experimental methods}

\subsection{Materials preparation}

The samples were prepared using $99.9 \%$ pure iron wire pieces from Balzers whose surfaces were polished to remove any surface oxide, rinsed with ethanol, dried, cut and weighed before being collected in silica ampoules together with $99.999 \%$ pure nuggets of tellurium from Goodfellow Cambridge Ltd. Before filling, ampoules were cleaned in an ultrasonic bath, rinsed with ethanol and dried.

Samples for isothermal heat treatments had a total mass of around 1 gram and samples for DTA-TGA studies had a total mass of around 80-110 mg to ensure a strong signal of weak thermal arrests. Ampoules were then backfilled with argon and sealed under primary vacuum. Further details of the isothermal heat treatments and DTA procedures follow in paragraphs 3.2-3.3. 


\subsection{Isothermal heat treatments and sample characterization}

For the isothermal heat treatments, an array of two to four sealed ampoules was rested at an incline inside a horizontal tube furnace $\left(T_{\max }=1773 \mathrm{~K}\right)$. The sample batch was held for two to four hours above the predicted melting temperature of the alloy, then held for one to four weeks at a selected temperature (848 to $1142 \mathrm{~K}$ ). At the end of the treatment, the sample array was pulled out of the furnace and quenched in cold water. A decision was made not to crush the ampoules upon retrieval in order to a) avoid destroying the microstructure of the very brittle samples, b) limit oxidation; with these factors in mind, the possibility of a non-equilibrium state was considered during analysis.

Retrieved samples were cold set in resin pellets, which after polishing were coated with a thin carbon layer by carbon fiber wire flash pulse prior to Scanning Electron Microscopy (SEM) analysis. The polishing was done with grit 800,1200 and $2000 \mathrm{SiC}$ paper, followed by diamond suspensions of 9,6 and finally $1 \mu \mathrm{m}$ particle size.

Samples were then studied via Light Optical Microscopy (LOM) and SEM (Zeiss LEO 1450VP), and phase compositions were measured with Energy Dispersive Spectroscopy (EDS). More accurate tieline determination was performed using a Cameca SX50 microprobe with Wavelength Dispersive Spectroscopy (WDS) detectors. When the solid phase composition seems uniform, it is regarded as equilibrated and the average of the flat bulk composition is taken as the solubility limit. In case the composition profile has a linear shape, it is not at equilibrium, but treated as a diffusion couple and the phase boundary evaluated from extrapolation of the composition to the interface. Most samples showed no to slight reaction with the silica ampoules, which is expected from liquid tellurium, and the alloys held isothermally in equilibrium with liquid had clearly reacted. Therefore, in all WDS analyses oxygen and silicon contaminations were also searched for; silicon contamination above the detection limit was never found. When uniform oxygen traces were observed, the composition was normalized to the Fe-Te content to best approximate the binary solubility.

\subsection{Differential Thermal Analysis}

A Setaram Setsys 16/18 DTA-TGA machine was used to confirm phase boundaries of the Fe-Te system, support a study of the nature of the gamma phase, and to find the believed to be eutectoid decomposition of $\delta$ - $F e_{0.75} T e$ into $\delta^{\prime}-F e_{0.67} T e$. Since the Fe-rich liquidus had not yet been found, a sample was prepared to attempt identifying that as well.

The temperature was calibrated using the melting points of lead, zinc, silver and gold standards from SETARAM placed in alumina crucibles. For silver and zinc, platinum lids covered the crucibles to limit mass loss. For each run with alloys, sealed silica ampoules were placed in the bottom of open alumina crucibles: one containing an Fe-Te sample, and one an empty reference ampoule. To check the delay in heat conduction through the silica ampoule to the bottom of the alumina crucible, a measurement was performed on gold at 5,3 and $1 \mathrm{~K} / \mathrm{min}$; a rather constant temperature offset from the calibration measurement of $0.4 \mathrm{~K}$ was found and thus subtracted from all subsequent measurements on alloy samples.

All alloy samples were melted in the machine for 30 to 40 minutes followed by cycles of heating and cooling programmed at rates of 5,3 and 2 or $1 \mathrm{~K} / \mathrm{min}$. Argon was used as the carrier- and furnace protection gas together with a closed coolant circuit of water kept at $20^{\circ} \mathrm{C}$. Due to a lack of calibration standards that do not experience significant supercooling, the apparatus was not calibrated for cooling cycles. The methodology recommended by Boettinger et al. was followed for the sampling of onsets and offsets of reactions [39]. 


\subsection{X-ray Diffraction and structure refinement}

$\mathrm{X}$-ray Diffraction (XRD) was performed on some of the samples in order to verify present phases, as well as attempt to identify the crystal structure of the $\gamma$ phase and the space group of the $\delta$ phase. FT51_T2, FT54_S and FT55_X were machine-milled and the others milled by mortar and pestle. Powders were then filtered using a $20 \mu \mathrm{m}$ test sieve. A Brucker D8 Advance and a PANalytical X'Pert PRO diffractometer were used with a $\theta-2 \theta$ setup. Samples were spinned in order to improve the measurement statistics of the XRD patterns. For the first few samples a Cu X-ray tube was used. A knife was placed by the sample to mitigate diffusion at low angle, and the 1-dimensional linear Lynxeye detector cutoff energy was set above the energy of the Fe $K \alpha$ fluorescence line. Subsequently, a Co X-ray tube was used with an X'Celerator 1-dimensional detector. Both X-ray sources had a $K \alpha_{1}: K \alpha_{2}$ intensity ratio of 2:1.

Rietveld refinement was performed using the MAUD software $[40,41]$, with an isotropic size (Gaussian distribution)-strain (lorentzian contribution) model considering a Pseudo-Voigt line profilefunction with axial divergence [42]. Due to absorption by Te, the peak intensity decreases with higher angle; therefore, Fe site fractions could not be well refined, and were instead fixed at probable compositions particularly deduced by structure relaxation via DFT computation. Moreover, due to residual texturing effects including the observation of platelet phases, the Le Bail method [43] was used as structure factor model.

\section{Results and discussion}

\subsection{Phase diagram data from heat treatments}

Table 2 presents the prepared compositions and expected phases of the samples for isothermal heat treatments. The sample names identify two things: first, FT\# implies an Fe-Te sample of \# at\% Te. Second, suffixes denote purpose: $\mathrm{T}$ for tie-line determination, $\mathrm{S}$ for single-phase composition and $\mathrm{X}$ for crystal structure determination via XRD. A final number was added if several samples of the same composition were prepared. As can be seen in Table 2, some samples were heat treated for 4 weeks to ensure thermodynamic equilibrium at such low temperatures. Table 3 summarizes phase boundaries of two-phase samples evaluated from the composition analyses via EDS and WDS. The respective tie-lines are shown in Figure 2, imposed on the calculated phase diagram compared with published phase boundary data (see Part II: Thermodynamic modelling). Filled symbols represent the prepared average sample compositions (Table 2), and empty symbols represent the evaluated phase boundary compositions (Table 3 ). The tie-lines are overall consistent with available solubility data.

Most heat treated samples showed no to small interaction with the silica ampoule. Samples treated in equilibrium with liquid showed a thin, soot-like, dark layer on the inner wall of the ampoule; while a reaction had clearly taken place, the extent was deemed small enough to not affect the state of the bulk sample and the ampoules remained intact. The largest extent of reaction was seen in sample FT58_S2, being cratered with large semi-spherical bubbles. The outer rim of the sample showed a clear and uniform, about $5 \mu \mathrm{m}$ thick, region of $\beta$ phase composition. Analysis of the deposits on the ampoule revealed tellurium oxide particles. In all two-phase samples, oxygen was concentrated in the most Fe-rich phase, i.e. the phase with more vacant interstitial sites.

A discussion of the composition analysis of the individual heat treated samples follows, divided into different regions of the phase diagram with descending tellurium content.

\subsubsection{Samples of 77 to 65 at\% Te}

As seen in Figure 5, sample FT77_T consists of primary $\epsilon$ phase precipitates and a quenched liquid phase that solidified into $\epsilon$ dendrites and tellurium, in agreement with the phase diagram. A lack of 
grain boundaries in the quenched matrix phase signifies a possibly retained amorphous state. Precipitates of pure tellurium $<0.4 \mu \mathrm{m}$ in size were also observed embedded in the matrix. FT77_T showed slightly more reaction with the silica than other samples, with the exception of FT58_S2, due to both the higher tellurium content, and the partially liquid state of FT77_T during heat treatment. The sample-ampoule reaction resulted in a tellurium depletion about $10 \mu \mathrm{m}$ into the sample, which was deemed not to have significantly affected the average solid phase composition. The XRD powder pattern could not be refined due to very high noise as well as an oscillating background, possibly from amorphous tellurium. Reflections from $\epsilon$ phase and traces of pure Te were identified, but also traces of $\beta$ phase, the reason of which cannot be readily explained; it could be due to the interaction between liquid solution and the ampoule.

As seen in Figure 8, FT65_T contained large bands of pores as well as cracks delineating almost all $\delta^{\prime} / \epsilon$ phase boundaries. The $\epsilon$ areas were completely smooth while $\delta^{\prime}$ was cratered with surface damage from polishing (Figure 5 and Figure 8).

In both samples, EDS and WDS showed on average flat composition profiles in the phase interfaces, and they were regarded as equilibrated with a maximum data spread of \pm 0.5 at $\%$ Te for the $\delta^{\prime}$ phase and \pm 0.3 at\% Te for the $\epsilon$ phase (Table 3). No oxygen was found in the $\epsilon$ phase but there were detectable levels in $\delta^{\prime}$; oxygen signal peaks were mostly related to surface damage, which might explain the larger error in equilibrium bulk concentration of $\delta^{\prime}$.

\subsubsection{Samples of 54 to 51 at\% Te}

FT54_S was prepared with the aim to obtain a pure $\gamma$ phase; instead, what seemed to be a twophase equilibrium of $\beta+\delta$ was obtained. This may be due to the difficulty of nucleating $\gamma$, as has been noted before [19]. However, a foreign microstructure was observed in the phase region with composition consistent with the $\delta$ phase, shown in back-scattered electron imaging of Figure 3. The stripes seem to be aligned along the grain orientation (See Figure S1, Supplementary material), and were about $1 \mu \mathrm{m}$ wide, as can be seen in Figure S2. Due to a stripe width of about the same size as the affected zone of EDS and WDS analysis $(1 \mu \mathrm{m})$, discrete composition differences between the regions could not be accurately determined, but the minimum and maximum compositions found from 36 points in EDS were 55.3 at\% Te and 59.7 at\% Te; the former is close to the $\gamma$ phase $(54.2$ at\% Te), the latter seems consistent with the $\delta^{\prime}$ phase. The formation of $\delta^{\prime}$ on quenching is possible since the $\delta$ phase has previously been found to easily decompose into $\beta$ and $\delta^{\prime}$ on cooling [19]. FT51_T2 was prepared at a higher temperature in the $\beta+\gamma$ region, but again no phase region with a composition of the $\gamma$ phase was found. Here the $\delta$ phase fraction was much smaller, with fewer and finer Te-rich stripes, appearing to precipitate in and emanate from the $\beta+\delta$ phase boundaries (Figure 4). No such stripes were found in the two samples FT58_S1 and FT58_S2, prepared to be pure $\delta$ phase. This absence means that the striped microstructure may not merely be the partial decomposition of $\delta$ into $\delta^{\prime}$, since that would also have been observed in FT58_S1 and FT58_S2.

It is interesting to note that the $\delta$ phases in samples FT54_S and FT51_T2 grow in $\mu \mathrm{m}$ size sheets, similarly to what is usually called 2D crystals (see Figures S3-S8, Supplementary material). This is common for the NiAs structure family of transition metal-chalcogenides that tend to grow in layers $[44,45]$. The actual crystal thickness cannot be deduced from the SEM images, since they may be thinner than is visible (See Figure S9 for magnification). The BSE image of Figure S10 shows that the striped structure discussed above is not related to individual layers of $\delta$ phase, since they are here seen to cross over several crystals. This indicates that the stripes probably formed later than the precipitation of $\delta$ phase. With the above discussion in mind, it is possible that the $\gamma$ phase is a NiAsrelated structure, and forms by diffusion over short distances in the $\delta$ phase. This could explain the preferred formation of the structure only in $\delta$ phase regions, and the parallel orientation. 
The high average oxygen content of FT54_S, shown in Table 3 to be about twice the detection limit of around $0.2 \mathrm{wt} \%$, is not negligible. Indeed, oxygen seems associated with the $\beta$ phase. All strong oxygen signals are found at surface effects, e.g. cracks, pits, and scratches. The composition analyses of the $\beta / \delta$ interfaces of both FT54_S and FT51_T2 showed a small composition gradient 5-10 $\mu \mathrm{m}$ into the $\beta$ phase followed by a flattening of the profile into the bulk of the phase, with a spread of \pm 0.5 at\% Te. This gradient may have two explanations; either it is a result of iron diffusion during precipitation of the observed striped microstructure, or the sample never reached thermodynamic equilibrium. The normalized average of the flat portion of the profile was used as the phase boundary of the $\beta$ phase, with large accepted error, and they were rather consistent with the tielines by Ipser et al. [19].

The diffraction patterns of these samples showed high levels of noise, peak broadening and decaying peak intensity due to absorption by Te (see figures S11 and S12, Supplementary material). Rietveld refinement could match most reflections with the $\beta$ and $\delta$ phases, with rather low accuracy due to the broadening (see Table 4 for the results). The a parameter of the $\beta$ phase is consistent with literature [12], while the c parameter deviates. The space group of $\delta$ was deduced from the rietveld refinement of sample FT55_X, as will be detailed below. Broadening was not completely accounted for in FT54_S, since crystal size would not converge well given the tricky distribution of data points in the pattern. Additional low-angle peaks were found at $22.6^{\circ}$ and $24.9^{\circ}$, exclusively present in all machine-milled samples. They seem to be a convolution of both discrete and broad peaks. The structure that best matches the additional peaks is $\mathrm{Fe}_{2} \mathrm{O}_{6} \mathrm{Te}$ of space group $\mathrm{P} 42 / \mathrm{mnm}$ (Figure S12); the sample was probably oxidized during milling. One small peak at $27.5^{\circ}$ remains unmatched. Sample FT54_S had one abnormally intense peak associated with the (200) reflection of the $\delta$ phase.

\subsubsection{Sample of 55 at\% Te}

Sample FT55_X, of a composition in the $\beta+\delta$ region close to the tentative $\delta$ phase boundary, was treated isothermally at $575^{\circ} \mathrm{C}$ for 4 weeks, in order to deduce if the sample contains hexagonal $\delta^{\prime}$ or monoclinic $\delta$ phase. This sample was more efficiently quenched by breaking the ampoule on retrieval.

WDS analysis of the sample was inconclusive due to bad focus resulting in a very low sum of wt\%. As seen in Table 3 this gave a standard deviation of 5 at\% Te. The tie-line, as shown in Figure 2, can therefore not be trusted. Such a shape of the phase diagram could be explained if the invariant of $\gamma$ phase formation were in fact the eutectoid $\delta \rightarrow \beta+\delta^{\prime}$ transition; however, Ipser et al found the $\delta$ phase to be stable below this temperature.

The XRD analysis showed mostly $\delta$ phase, and a possible trace amount of $\beta$ phase, as also seen in the LOM image of Figure 9. A possible monoclinic modification of the hexagonal NiAs type structure is the $C c$ space group, and an initial refinement found that an ordered superstructure of the $C 2 / \mathrm{m}$ space group can also fit the pattern. The latter unit cell was relaxed via DFT, as further detailed in the modelling Part II, resulting in more realistic atomic positions. This structure was further refined via rietveld analysis, and compared with the $C \mathrm{c}$ and $P 6_{3} / \mathrm{mmc}$ space groups as shown in Figure A1 (Appendix); space group $P \overline{3} / m 1$ fit identically well as $P 6_{3} / m m c$, and is therefore left out. While $C c$ and $P 6_{3} / \mathrm{mmc}$ can equally well fit the same peaks, $C 2 / \mathrm{m}$ accounts for additionally two otherwise unmatched peaks, one of which is the one at $27.5^{\circ}$ also found in FT51_T2 and FT54_S. As seen in Table 4 , the weighted profile R-factors $\left(R_{w p}\right)$ show that although the space groups fit the pattern almost equally well, $C 2 / m$ gives the better fit. Note that the high noise, and the large unmatched peaks makes the Rwp less useful than a simple qualitative comparison. The final crystallographic data on the $\delta$ phase of sample FT55_X are detailed in (Table A1, Appendix). 


\subsubsection{Samples of 47 to 25 at\% Te}

FT25_T1 and FT25_T2 were prepared in the $\alpha-F e+\beta$ region. As seen in Figure 6 and Figure 10, the analyzed samples showed cores of pure iron with thick $\beta$ phase layers. With the assumed limited diffusion of Te through $\mathrm{Fe}$, the samples have not reached uniform composition, and are therefore not at equilibrium. Although the $\beta$ phase has not reached an equilibrium iron content, the sample may be treated as a diffusion couple for the determination of Te solubility in $\alpha-F e$. The last points in the $\alpha-F e$ phase of the composition profiles before the $\alpha-F e+\beta$ interface were rather consistent over several line scans, and taken as the solubility limit, consistent with the tie-line published by Ipser et al (Figure 2).

In addition to these samples, FT47_S1 and FT47_S2 were prepared in the $\beta^{\prime}$ single-phase region. Retaining some $\beta^{\prime}$ phase was attempted, even though failure was expected. Judging by the EDS analysis FT47_S1 had a uniform composition. These samples also contained sheet crystals of $\mu \mathrm{m}$ size, similarly to the $\delta$ phases, which is expected from PbO structure chalcogenides [46]. SEM and LOM images revealed layered growth in the entire sample, as shown in Figure 7. Both samples showed parallel cracks in the metallographic analyses, probably aligned with the $2 \mathrm{D}$ crystal planes since the ordered $\beta$ phase should have weak bonds between the Te-Te layers lacking interstitial iron.

Metallography of FT47_S2 showed a similar appearance and uniform composition. As seen in Figure S13 (Supplementary material), XRD analysis of FT47_S2 showed complete decomposition into the $\beta$ phase, as expected. The lattice parameters deduced from rietveld refinement (Table 4) correspond well with available literature [12]. 
Table 2: A priori properties of isothermally heat treated Fe-Te samples. *: Rounding error in prepared composition are all $<0.007 \mathrm{at} \% \mathrm{Te}$.

\begin{tabular}{c|ccc|ccc|c}
\hline & \multicolumn{3}{c}{ Prepared composition } & \multicolumn{2}{c}{ Heat treatment } & \\
Sample ID & at\% Te* & wt\% Te & Mass [mg] & \multicolumn{1}{c}{ T [K] } & Time [h] & \multicolumn{1}{c}{ Expected phase(s) } \\
\hline FT77_T & 76.83 & 88.34 & 1093 & 866 & 672 & $\epsilon+$ Liq \\
FT65_T & 65.33 & 81.15 & 1125 & 866 & 672 & $\delta^{\prime}+\epsilon$ \\
FT58_S1 & 58.37 & 76.21 & 1167 & 954 & 331 & $\delta$ \\
FT58_S2 & 58.41 & 76.24 & 1118 & 1043 & 330 & $\delta$ \\
FT55_X & 55.13 & 73.74 & 1588 & 848 & 672 & $\beta+\delta$ \\
FT54_S & 54.09 & 72.92 & 928 & 954 & 331 & $\gamma$ \\
FT51_T1 & 50.99 & 70.39 & 865 & 1142 & 336 & $\beta^{\prime}+$ Liq \\
FT51_T2 & 51.01 & 70.41 & 888 & 1043 & 330 & $\beta+\gamma$ \\
FT47_S1 & 47.05 & 67.00 & 1083 & 1142 & 336 & $\beta^{\prime}$ \\
FT47_S2 & 47.12 & 67.06 & 1047 & 1142 & 168 & $\beta^{\prime}$ \\
FT25_T1 & 25.58 & 43.99 & 918 & 954 & 331 & $\alpha F e+\beta$ \\
FT25_T2 & 24.80 & 42.97 & 911 & 1043 & 330 & $\alpha F e+\beta$ \\
\hline
\end{tabular}

Table 3: Condensed results of WDS composition analysis for tie-line determination. *: Sample machine milled and partially oxidized, probably into $\mathrm{Fe}_{3} \mathrm{O}_{4}$ and $\mathrm{Fe}_{2} \mathrm{O}_{6} \mathrm{Te}$

\begin{tabular}{|c|c|c|c|c|c|c|c|}
\hline \multirow{3}{*}{$\frac{\text { Sample ID }}{\text { FT77_T }}$} & \multirow{3}{*}{$\frac{\text { Region }}{\epsilon+L i q}$} & \multicolumn{5}{|c|}{ WDS wt\% oxygen } & \multirow{2}{*}{$\begin{array}{c}\text { Phases found } \\
\text { by XRD }\end{array}$} \\
\hline & & \multicolumn{2}{|c|}{ Boundary: composition [at\% Te] } & mean & $\max$ & mean sum-wt $t^{1} \%$ & \\
\hline & & $\epsilon: 68.3 \pm 0.3$ & $L: \mathrm{N} / \mathrm{A}^{2}$ & 0 & 0.24 & 100.44 & $\epsilon+T e, \operatorname{trace} \beta$ \\
\hline FT65_T & $\delta^{\prime}+\epsilon$ & $\delta^{\prime}: 63.3 \pm 0.5$ & $\epsilon: 66.8 \pm 0.3$ & 0.04 & 0.28 & 99.79 & Not analyzed \\
\hline FT55_X & $\beta+\delta ?$ & $\beta: 49.43 \pm 5$ & $\delta: 59.88 \pm 5$ & 0.2 & 0.44 & 93.82 & $\delta$, trace $\beta^{*}$ \\
\hline FT54_S & $\beta+\delta$ & $\beta: 48.5 \pm 0.5$ & $\delta: 57.0 \pm 0.7^{3}$ & 0.41 & 1.52 & 101.27 & $\beta+\delta / \delta^{*}$ \\
\hline FT51_T2 & $\beta+\delta$ & $\beta: 48.4 \pm 0.5$ & $\delta: 55.2 \pm 0.5^{3}$ & 0.22 & 1.11 & 101.3 & $\beta+\delta / \delta^{\prime *}$ \\
\hline FT25_T1 & $\alpha F e+\beta$ & $\alpha-F e: 0.3 \pm 0.05$ & $\beta: N / E^{4}$ & 0.22 & 1.43 & 102.04 & Not analyzed \\
\hline FT25_T2 & $\alpha F e+\beta$ & $\alpha-F e: 0.7 \pm 0.4$ & $\beta: N / E$ & 0.10 & 1 & 102.85 & Not analyzed \\
\hline
\end{tabular}

Table 4: Results of powder pattern refinement on selected samples, with optimized lattice parameters and weighted profile $R$-factor (Rwp). $\beta$ angles were fixed, since the parameter does not converge with the given quality of measurement.

\begin{tabular}{cc|cccc|c}
\hline $\begin{array}{c}\text { Sample ID, } \\
\text { target }\end{array}$ & Space group & $a[\AA]$ & $b[\AA]$ & $c[\AA]$ & $\beta\left[{ }^{\circ}\right]$ & $R_{w p} \%$ \\
\hline FT47_S2, Cu & $P 4 / n m m: 2$ & $3.821 \pm 2 \mathrm{E}-4$ & - & $6.266 \pm 2 \mathrm{E}-4$ & - & 48.8 \\
FT51_T2, Co & $P 4 / n m m: 2$ & $3.84 \pm 6 \mathrm{E}-4$ & - & $6.33 \pm 0.002$ & - & 40.1 \\
& $C 2 / m: b 1$ & $6.70 \pm 0.005$ & $4.10 \pm 6 \mathrm{E}-4$ & $10.94 \pm 0.006$ & 90.65 & \\
& $P 42 / m n m$ & $4.66 \pm 0.001$ & - & $9.39 \pm 0.004$ & & \\
FT54_S, Co & $P 4 / n m m: 2$ & $3.82 \pm 0.002$ & - & $6.45 \pm 0.005$ & - & 92.1 \\
& $C 2 / m: b 1$ & $6.70 \pm 0.003$ & $4.08 \pm 8 \mathrm{e}-4$ & $10.94 \pm 0.006$ & 90.65 & \\
& $P 4_{2} / m n m$ & $4.67 \pm 7 \mathrm{E}-4$ & - & $9.39 \pm 0.006$ & & \\
FT55_X, Co & $C 2 / m: b 1$ & $6.70 \pm 0.007$ & $3.86 \pm 0.005$ & $11.23 \pm 0.005$ & 90.65 & 42.3 \\
& $C c: b 1$ & $3.876 \pm 4 \mathrm{E}-4$ & $6.648 \pm 6 \mathrm{E}-4$ & $5.585 \pm 2 \mathrm{E}-6$ & 90.2 & 44.4 \\
& $P 6_{3} / \mathrm{mmc}$ & $3.851 \pm 0.001$ & - & $5.603 \pm 0.003$ & - & 44.5 \\
& $P 4_{2} / \mathrm{mnm}$ & $4.65 \pm 0.001$ & & $9.36 \pm 0.006$ & & \\
\hline
\end{tabular}

\footnotetext{
${ }^{1}$ The sum includes Fe, Te, Si and $\mathrm{O}$

${ }^{2}$ The dendritic region, was not analyzed in FT77_T.

${ }^{3}$ Average composition of two-phase microstructure that used to be $\delta$ phase

${ }^{4}$ Not in equilibrium.
} 


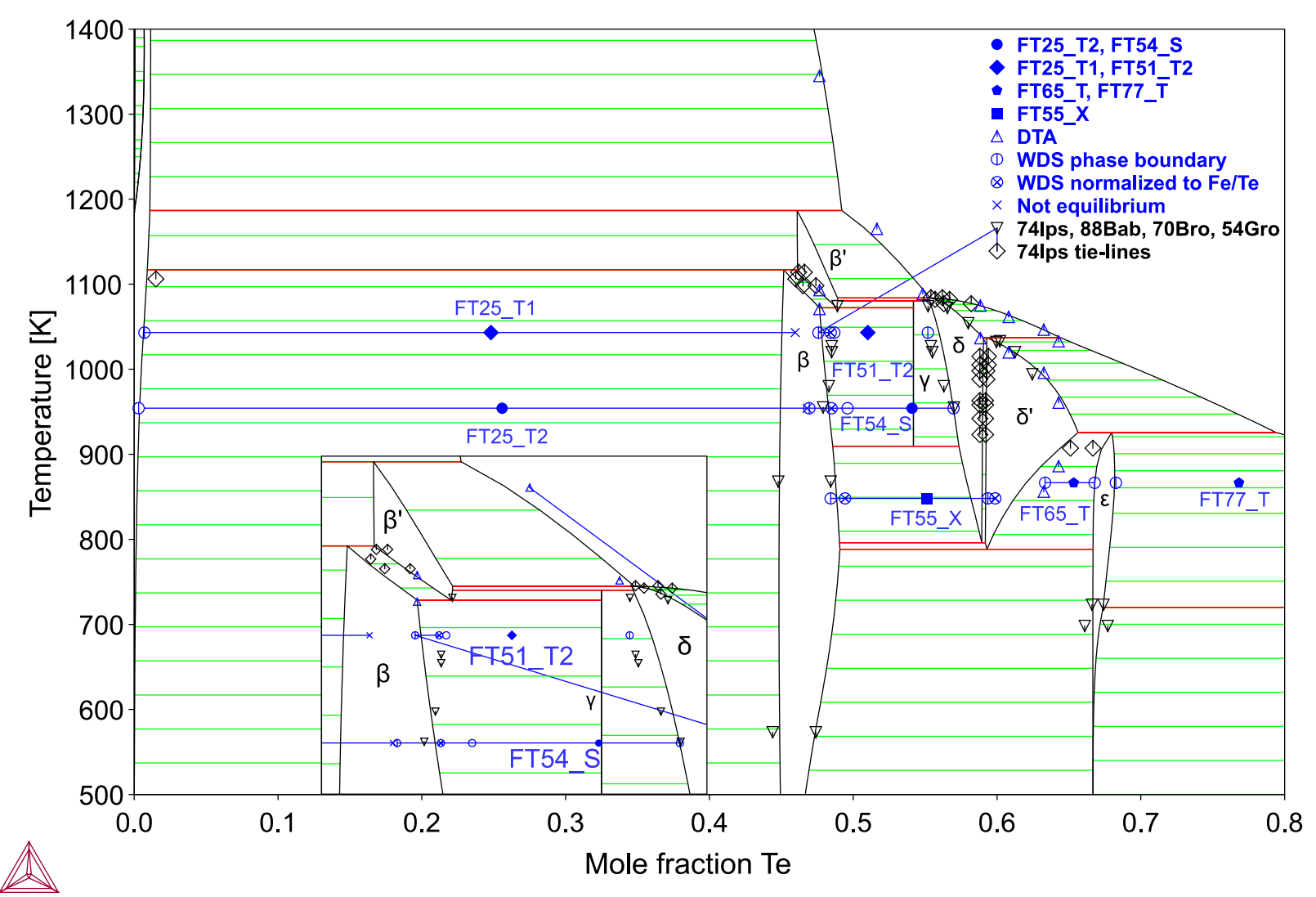

Figure 2: Calculated Fe-Te phase diagram from Part II: Thermodynamic modelling, compared with tie-lines from isothermal heat treatments, phase boundaries from DTA, and selected published data

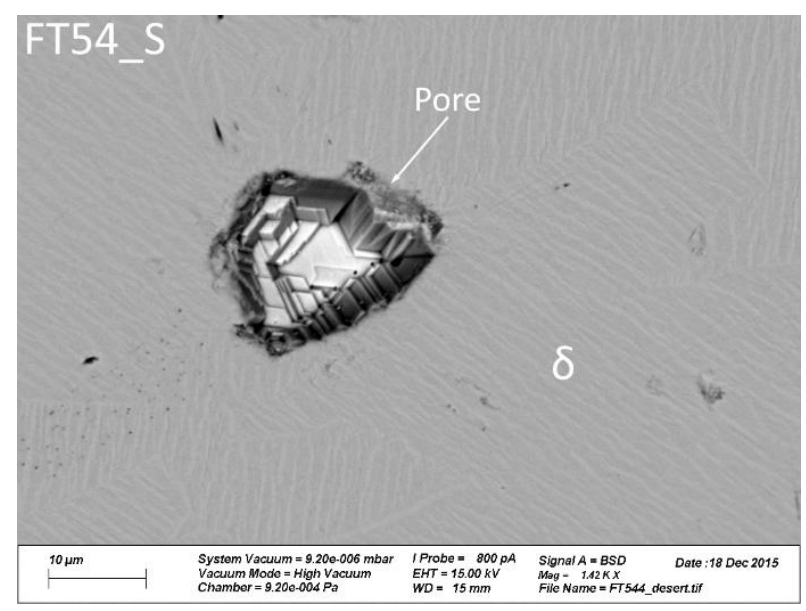

Figure 3: BSE image of the striped microstructure in sample FT54_S. Image shows stripes of varying direction in different grains around a pore.

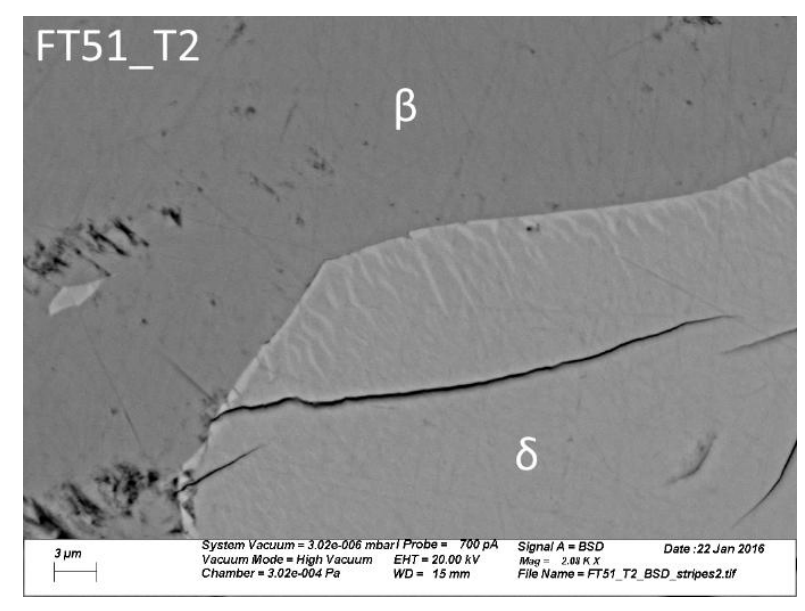

Figure 4: BSE image of boundary between $\beta$ (dark gray) and $\delta$ (light gray) phases in sample FT51_T2. Here the stripe precipitates seem to emanate from the phase boundary. 


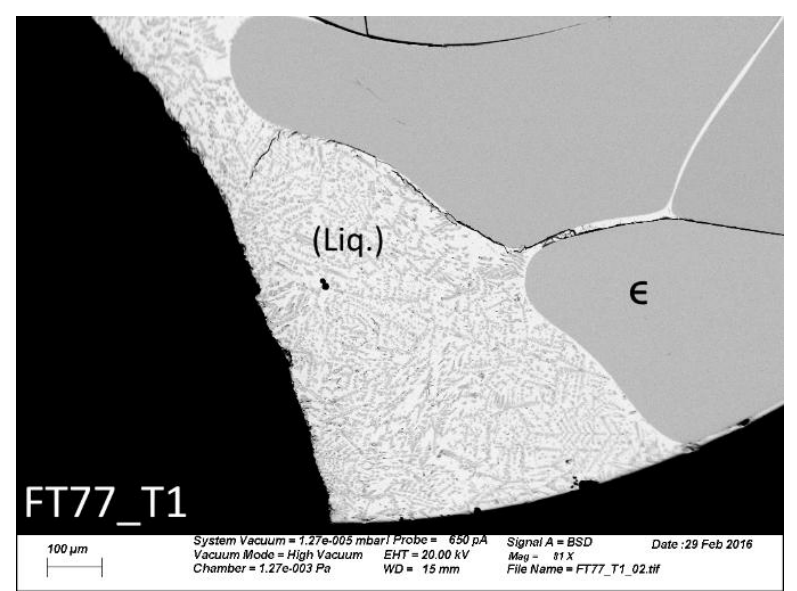

Figure 5: BSE image of a corner of sample FT77_T. $\epsilon$ phase has been in equilibrium with liquid, which has on cooling solidified into $\epsilon$ dendrites and tellurium.

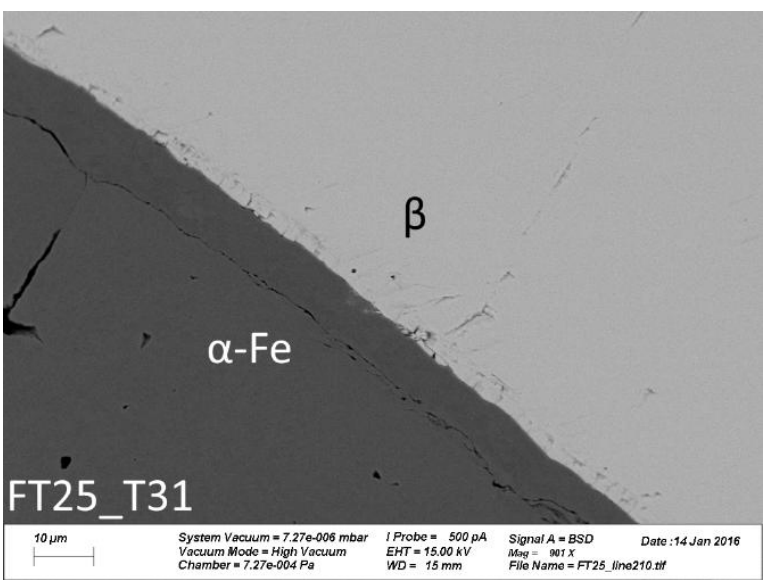

Figure 6: BSE image of FT25_T1, magnified on the boundary between the iron core and the surrounding scale of $\beta$ phase.

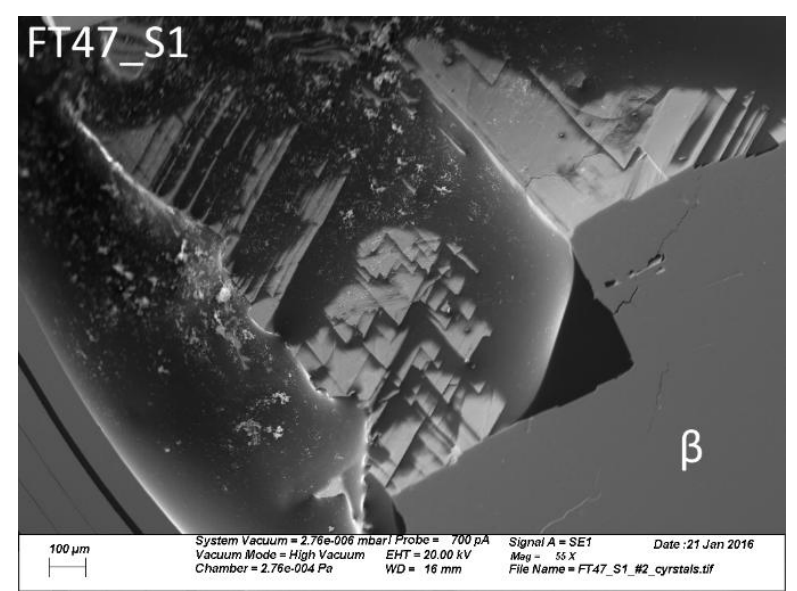

Figure 7: SEM image taken between precipitates in sample FT47_S1, showing the layers of the $\beta$ phase.

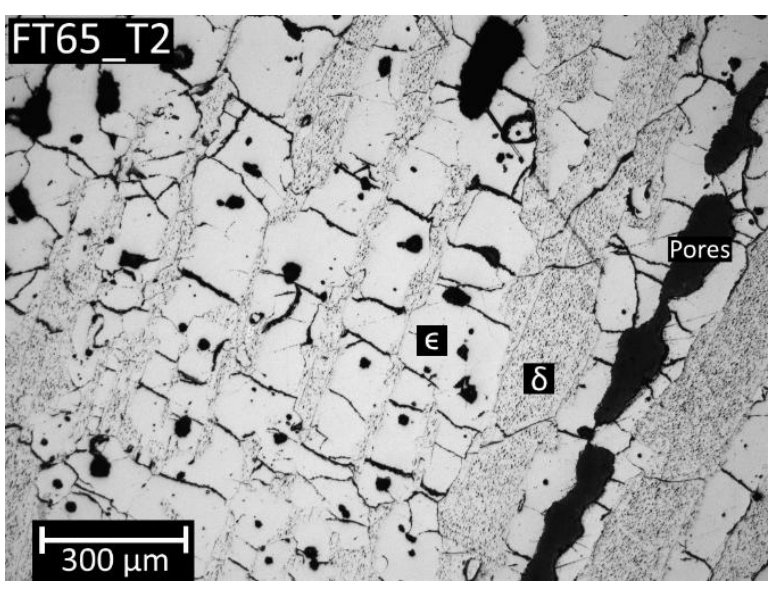

Figure 8: LOM image of sample FT65_T. The $\epsilon$ phase has precipitated between bands of $\delta$ phase, with significant porosity and intergranular cracking.

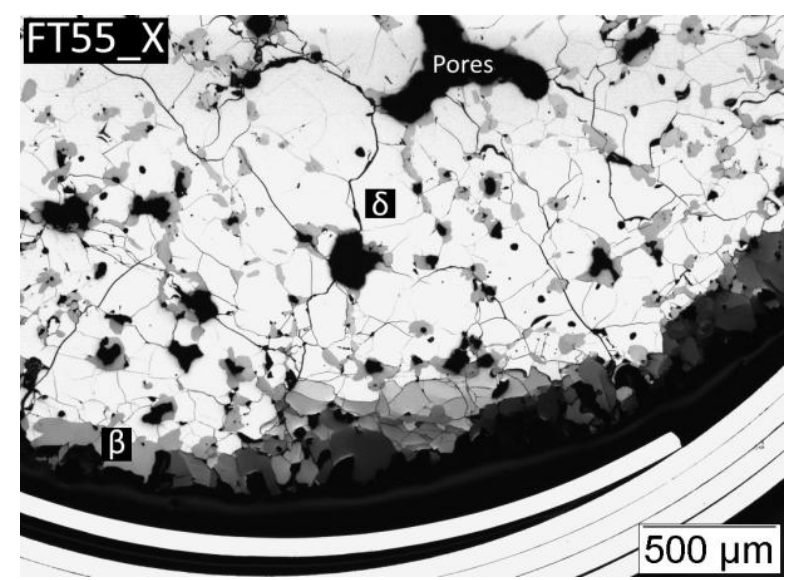

Figure 9: LOM image of FT55_X. Bright regions are $\delta$ or $\delta^{\prime}$ phase, small gray precipitates $\beta$ phase.

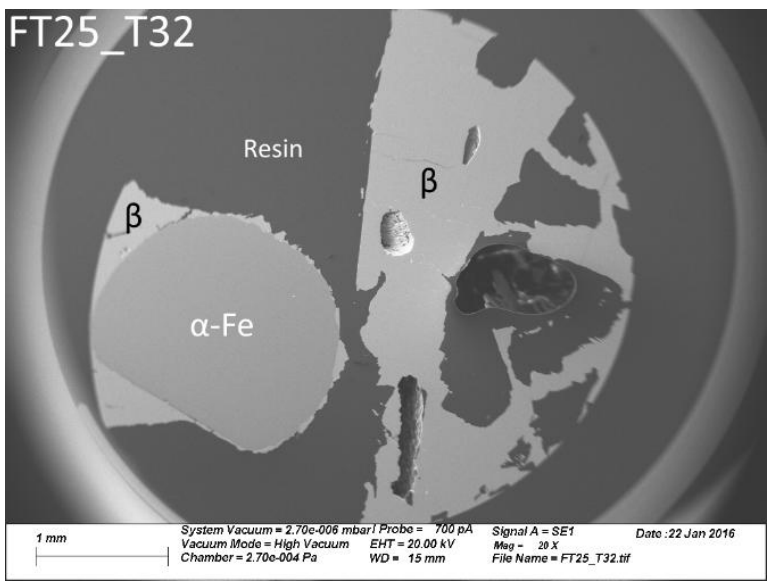

Figure 10: SEM image of sample FT25_T2. A piece of iron wire is surrounded by $\beta$ phase, and a separate piece entirely consists of $\beta$ phase. 


\subsection{Phase transition data from DTA}

Thermograms of Fe-Te alloys, normalized to linear baselines, are presented in Figure 11 superimposed over the calculated phase diagram. The baselines are positioned roughly at the corresponding sample compositions, and red markers indicate where the onset of reaction (deviation from baseline) or end of reaction (local maximum of heat curve) were sampled. All invariant reactions are consistently found a few degrees lower than previous DTA studies. This could be due to changing standards of sampling; earlier it was common to use the extrapolated onset of reaction, as is done for pure elements, while presently it is accepted to sample the first deviation from the baseline as the onset of reaction [39], as was done in this work.

Table 5 shows the observed reactions from the DTA measurements. All measurements show good agreement with the phase diagram proposed by Ipser et al. (Figure 1a), indicating that the sample compositions were successfully prepared. Chemical analysis found no silicon dissolved in the samples; the results however over-predicted the composition by 1.56-4.37 at\% Te with a relative error of $3 \%$. Those compositions are highly improbable, since the very clear thermal effects would not have been observed if the chemical analyses had been accurate, indicating a possible contaminant or anomaly during the analyses. If this contaminant were oxygen, either from remaining oxide of the pure materials or reaction with the silica ampoules, the good agreement with previous experiments indicate that it does not significantly offset the reaction temperatures from the binary phase diagram boundaries.

While Ipser et al. did not find the iron rich liquidus, this work raised the studied temperature of sample FT47_D; thus a small but clear local maximum was observed before returning to the baseline, i.e. the liquidus (for a magnification, See Figure S14 in Supplementary material). Thermal effects on heating were found consistent with the $\beta^{\prime}$ phase peritectoid formation, solvus and peritectic melting. The solidus could not be clearly determined, since the diffuse onset of melting was difficult to quantify (labeled too weak in Table 5). This experiment, and all subsequent ones, showed periodic oscillations in the TG and heat curves, effectively hiding any small thermal effect in thermograms of cycles at $1 \mathrm{~K} / \mathrm{min}$. Modification of the setup to use tap water to cool the furnace mitigated the issue. This change of setup was not found detrimental to the calibration.

FT51_D experienced several weak steps and bumps in the baseline on heating and cooling, one of which was consistent with the suggested formation of the $\gamma$ phase [19]. This roughly lambda-shaped peak was clear in FT54_D. Chiba believed that this peak, found in FeTe and FeTe $\mathrm{F}_{1.08}$, was an anomaly related to the strange shape of the $\delta$ phase solvus (Peak B in [14]). Chiba related the peak in $\mathrm{FeTe}_{1.33}$ to this anomaly, but it was actually the solvus line. The invariant arrests of $\psi$ phase and $\delta$ phase decomposition were not separated on heating in FT51_D, although after several runs peak separation was observed on cooling. They separated inconsistently between cycles, and therefore the additional peaks could be irreversible artifacts. The FT54_D measurements were also focused on finding the $\delta^{\prime}$ to $\delta$ transition without success. As a result, FT58_D was prepared at the hypothesized eutectoid composition of said reaction, but the baseline was completely flat in the region. It was, however, noted that all samples at lower compositions than the predicted $\beta+\epsilon \rightarrow \delta^{\prime}$ eutectoid showed a second onset in the peak assigned to the just mentioned reaction.

Returning to the analysis of reactions above and below the $\gamma$ phase, customized silica ampoules were created to fit directly to the DTA thermocouples in order to obtain a more highly resolved signal, and FT54_D2 was thusly analyzed. Figure 12 shows the slowest cycle of heating and cooling, normalized to linear baselines. It can be seen in Figure 12 that the final local maximum on heating, and the first onset of reaction on cooling, i.e. the liquidus, coincide well. Subsequent reactions on cooling, 
however, do not coincide, thus indicating supercooling; all DTA samples exhibited this, at least to some extent. The second onset is very clearly seen, on peak (1), as well as the heat of $\gamma$ phase formation, peak (2); the higher-temperature peaks were now separated into the decomposition of $\gamma$ and $\delta$ phases on heating (Figure 13). The apparatus was not yet calibrated for these crucibles, so in order to identify the separated peaks, the heating spectrum was normalized between four well known reactions in the phase diagram: onset (1) in Figure 12 was fixed to the known $\beta+\epsilon \rightarrow \delta^{\prime}$ invariant; onset (2) was fixed to the $\beta+\delta \rightarrow \gamma$ invariant; onset (3) in Figure 13 was fixed to the $\beta+\gamma \rightarrow \beta^{\prime}$ eutectoid reaction; and local maximum (7) was fixed to the liquidus. This normalization was sufficient to give an approximate linear correlation between measured and real temperature. As a result, peak (6) lined up approximately with the invariant $\beta^{\prime}+\delta \rightarrow L$, and peak (5) aligned with our other measurements of the $\gamma \rightarrow \beta^{\prime}+\delta$ invariant. The respective magnitudes of peak (5) and (6) also support this finding. This leaves offset (4) unassigned to any presently known reaction; while it is small, it is clearly preceded by a short interval at baseline level, then turning into a linear slope that may be extrapolated towards the local maximum of the liquidus (see dashed line, Figure 13). This looks characteristic of going from a single-phase region, through a series of two-phase regions divided by two invariant arrests, before eventually completely melting. This may suggest that the $\gamma$ phase is not stoichiometric, but has a narrow homogeneity range, and that this sample happens to pass through a single-phase region between peak (3) and (4), after which one briefly passes through a $\gamma+\delta$ two-phase region before $\gamma$ decomposes at peak (5). Another possible explanation is that the $\delta$ phase somehow extends to be stable above the $\gamma$ phase. This is not probable, however, since a rather high-temperature $\delta$ phase solvus was found in FT58_D. One should note how weak the $\gamma$ formation peak (2) is, which also supports the possibility that the $\gamma$ phase is similar to the $\delta$ phase.

FT58_D, FT61_D, FT63_D and FT64_D were consistent with the liquidus, solidus and peritectic invariants found by Ipser et al. [19]. The rightmost solvus of the $\delta$ phase was found in FT63_D and FT64_D, while the onset was very weak in FT61_D, and therefore ignored. These data agree more with the tie-line determined by Ipser et al. and the tie-line of sample FT65_T than the phase boundary determined by Chiba [14]. 
Table 5: Thermal effects of the Fe-Te system found in this work via DTA. Reference composition only shown when different from that of this work; irrelevant for invariant reactions. *: Two invariant reactions very close together, peaks not separated. **: Maximum rounding error in prepared composition.

\begin{tabular}{|c|c|c|c|c|c|}
\hline Sample ID & $a t \% T e^{* *}$ & $\begin{array}{c}\text { Measured } \\
T \pm 1[K]\end{array}$ & $\begin{array}{c}\text { Ref. T[K] } \\
(a t \% \mathrm{Te})[19]\end{array}$ & $\begin{array}{l}\text { Type of } \\
\text { reaction }\end{array}$ & $\begin{array}{c}\text { Phase transformation } \\
\text { on cooling }\end{array}$ \\
\hline \multirow[t]{4}{*}{ FT47_D } & $47.65 \pm 0.07$ & 1345 & N/A & Liquidus & $L \rightarrow \alpha-F e$ \\
\hline & & 1191 & 1187 & Peritectic & $\alpha-F e+L \rightarrow \beta^{\prime}$ \\
\hline & & 1092 & $1093(47.6)$ & Solvus & $\beta^{\prime} \rightarrow \beta$ \\
\hline & & 1071 & 1073 & Eutectoid & $\beta^{\prime} \rightarrow \beta+\gamma$ \\
\hline \multirow[t]{6}{*}{ FT51_D } & $51.64 \pm 0.10$ & 1165 & 1161 (51.65) & Liquidus & $L \rightarrow \beta^{\prime}$ \\
\hline & & 1081 & 1082 & Peritectoid* & $\beta^{\prime}+\delta \rightarrow \gamma$ \\
\hline & & 1072 & 1073 & Eutectoid & $\beta^{\prime} \rightarrow \beta+\gamma$ \\
\hline & & 910 & 909 & Eutectoid & $\gamma \rightarrow \beta+\delta$ \\
\hline & & 797 & N/A & Eutectoid & $\delta \rightarrow \beta+\delta^{\prime}$ \\
\hline & & 790 & 792 & Eutectoid & $\delta^{\prime} \rightarrow \beta+\epsilon$ \\
\hline \multirow[t]{5}{*}{ FT54_D } & $54.83 \pm 0.10$ & 1089 & $1090(54.90)$ & Liquidus & $L \rightarrow \beta^{\prime}$ \\
\hline & & 1078 & 1082 & Peritectoid & $\beta^{\prime}+\delta \rightarrow \gamma$ \\
\hline & & 909 & 909 & Eutectoid & $\gamma \rightarrow \beta+\delta$ \\
\hline & & 795 & N/A & Eutectoid & $\delta \rightarrow \beta+\delta^{\prime}$ \\
\hline & & 789 & 792 & Eutectoid & $\delta^{\prime} \rightarrow \beta+\epsilon$ \\
\hline \multirow[t]{3}{*}{ FT58_D } & $58.84 \pm 0.06$ & 1075 & 1075 (59.05) & Liquidus & $L \rightarrow \delta$ \\
\hline & & 1037 & Not comparable & Solidus & $L \rightarrow \delta$ \\
\hline & & 787 & 792 & Eutectoid & $\delta^{\prime} \rightarrow \beta+\epsilon$ \\
\hline \multirow[t]{4}{*}{ FT61_D } & $60.81 \pm 0.08$ & 1062 & $1061(61.25)$ & Liquidus & $L \rightarrow \delta$ \\
\hline & & 1037 & 1039 & Peritectic & $\delta+L \rightarrow \delta^{\prime}$ \\
\hline & & 1020 & 1020 (61.25) & Solidus & $L \rightarrow \delta^{\prime}$ \\
\hline & & 787 & 792 & Eutectoid & $\delta^{\prime} \rightarrow \beta+\epsilon$ \\
\hline \multirow[t]{5}{*}{ FT63_D } & $63.25 \pm 0.14$ & 1047 & 1052 (62.45) & Liquidus & $L \rightarrow \delta$ \\
\hline & & 1038 & 1039 & Peritectic & $\delta+L \rightarrow \delta^{\prime}$ \\
\hline & & 996 & $994(62.45)$ & Solidus & $L \rightarrow \delta^{\prime}$ \\
\hline & & 856 & N/A & Solvus & $\delta^{\prime} \rightarrow \epsilon$ \\
\hline & & 790 & 792 & Eutectoid & $\delta^{\prime} \rightarrow \beta+\epsilon$ \\
\hline \multirow[t]{4}{*}{ FT64_D } & $64.28 \pm 0.07$ & 1033 & $1038(64.50)$ & Liquidus & $L \rightarrow \delta^{\prime}$ \\
\hline & & 961 & N/A & Solidus & $L \rightarrow \delta^{\prime}$ \\
\hline & & 886 & N/A & Solvus & $\delta^{\prime} \rightarrow \epsilon$ \\
\hline & & 789 & 792 & Eutectoid & $\delta^{\prime} \rightarrow \beta+\epsilon$ \\
\hline
\end{tabular}




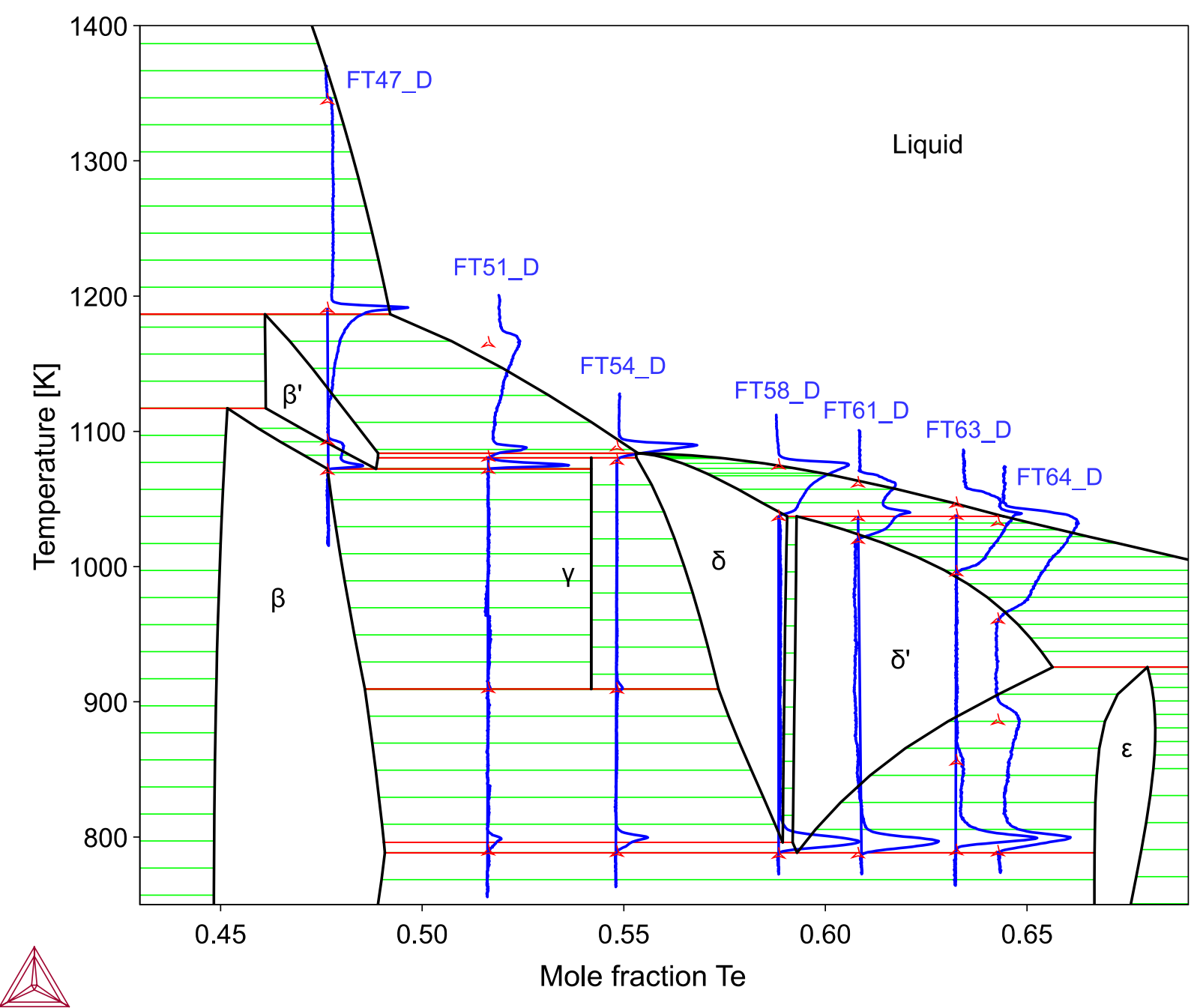

Figure 11: Calculated Fe-Te phase diagram with superimposed thermograms from the DTA heating cycles. Flat baselines mark sample compositions. Red marks show the average sampled temperature of reactions.

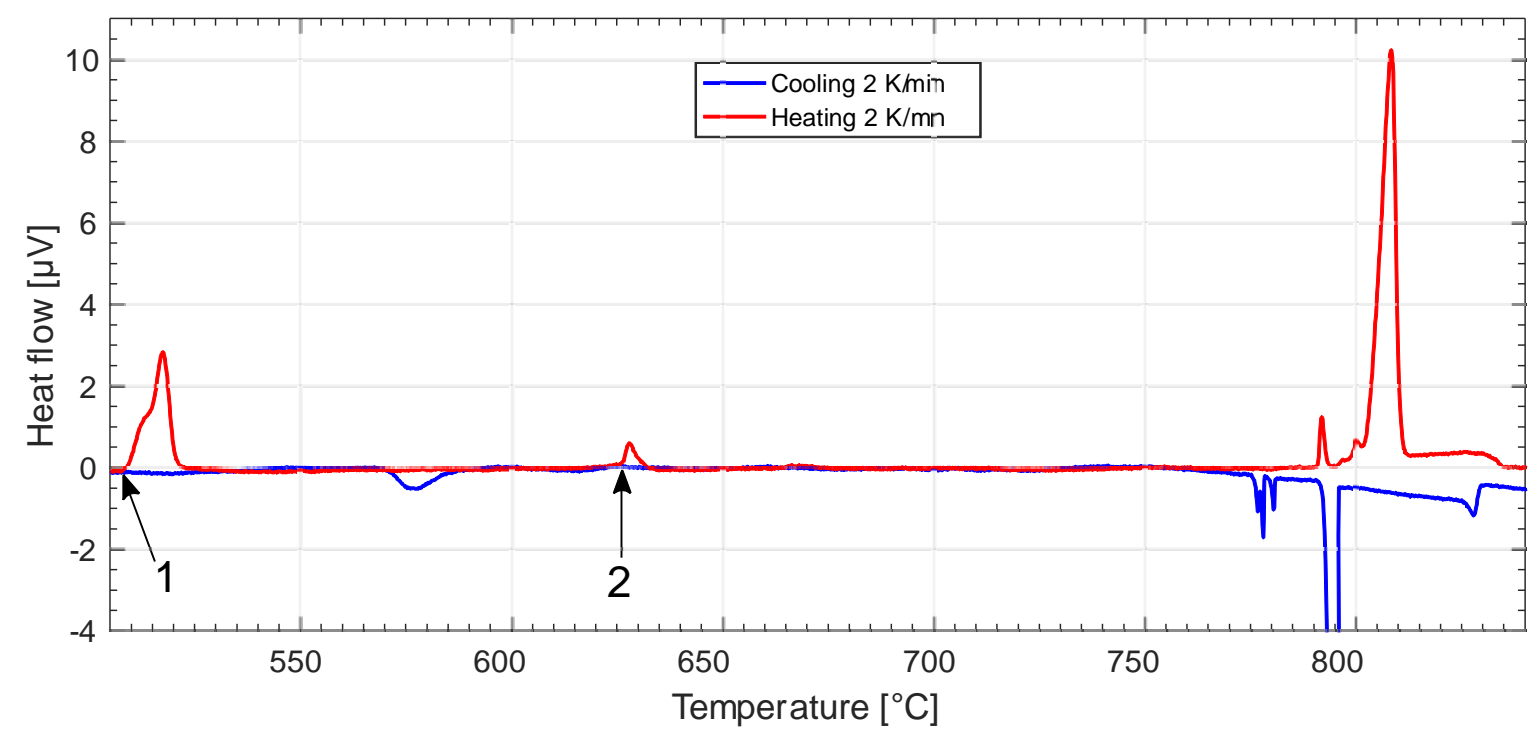

Figure 12: Thermogram of the slowest heating and cooling cycle of FT54_D2, normalized to a linear baseline. The liquidus aligns well while solidus and solid state reactions are supercooled. Note the clear second onset of reaction on peak numbered (1) that may pertain to the $\delta^{\prime} \rightarrow \delta+\beta$ reaction. Peak (2) believed to belong to the $\gamma$ phase is weak but clear. 


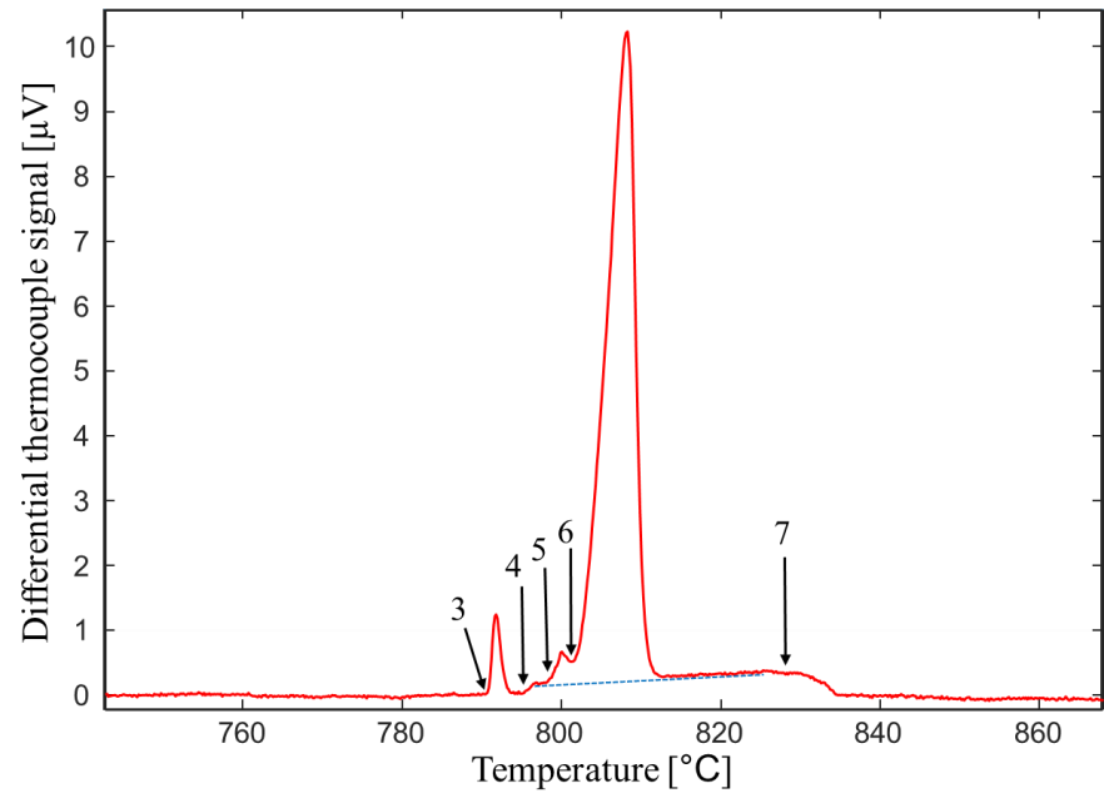

Figure 13: Magnification of the last group of heat signals during heating of FT54_D2 at $2 \mathrm{~K} / \mathrm{min}$. Dashed blue line is to aid heat curve interpretation. Probable reactions: (3) $\beta+\gamma \rightarrow \beta^{\prime}$. (4) Unknown. (5) $\gamma \rightarrow \beta^{\prime}+\delta$. (6) $\beta^{\prime}+\delta \rightarrow L$. (7) $\beta^{\prime}+L \rightarrow L$.

\section{Conclusions}

Tie-lines of the Fe-Te phase diagram have been determined by EDS and WDS measurements on isothermally heat-treated samples. Phase boundaries have been quantified from DTA measurements. Rietveld refinement of XRD powder patterns corroborated with DFT calculations (Part II: Thermodynamic Modelling) lead us to propose a new space group $C 2 / m$ of the $\delta$ phase.

With these new DTA and tie-line data, this work has contributed to an improved characterization of the phase boundaries of the Fe-Te system. We lowered most invariant arrests by a few degrees, found a point on the Fe-rich liquidus, found the probable eutectoid reaction between the $\delta$ and $\delta^{\prime}$ phases to lie very close to the eutectoid $\delta^{\prime}$ formation temperature, as well as adding $\delta$ and $\epsilon$ phase boundaries. We showed indications that the $\gamma$ phase may have a narrow homogeneity range, and metallographic studies note that the $\gamma$ phase may have a crystal structure related to the $\delta$ phase. If the striped microstructures found in our samples do relate to the $\gamma$ phase, the phase seems to form either in cooperative growth with the $\delta$ phase, or out of a parent $\delta$ phase. Regardless of the nature of the $\gamma$ phase, the related invariant arrests certainly exist. We highlight some key points for future studies of the system.

1) The phase boundaries of the $\beta^{\prime}$ phase were approximated from DTA measurements of invariant arrests [19], while less accurate solubility data estimated from XRD [13] suggest a congruent transition. We recommend for future studies to confirm the Fe-rich phase boundaries of the $\beta^{\prime}$ and $\beta$ phases, with rigorous sample preparation ensuring equilibrium. In addition, we recommend performing In-situ high-temperature XRD to confirm if the $\beta^{\prime}$ phase is indeed the same crystal structure as the ternary phase $\mathrm{Fe}_{0.28} N i_{0.28} T e_{0.44}$, as has been proposed in this work.

2) It would be useful to further verify that the space group of the $\delta$ phase is $C 2 / \mathrm{m}$ using better, high-energy diffraction methods, or for example Raman spectroscopy or EBSD.

3) The $\gamma$ phase seems to be related to the NiAs $(\delta)$ structure family. It could be useful to use $A b$ initio methods to suggest a stable crystal structure. In addition, a large number of samples 
for isothermal heat treatment can be prepared in order to metallographically analyze the striped microstructure further, e.g. via EBSD.

4) Furthermore, it would be useful to the modeling to design experiments to identify the presence of a liquid miscibility gap in the Fe-FeTe composition interval. This might prove challenging, since samples need to be contained in vessels that can withstand the reactive tellurium as well as up to $10-100 \mathrm{kPa}$ of vapor pressure.

The data gathered in this paper will be used in our subsequent publication Part II: Thermodynamic modelling for a critical thermodynamic assessment of the system.

\section{Acknowledgements}

The authors would like to thank the Swedish Research Council (Vetenskapsrådet) for the funding of the PhD project, which contributes to the SAFARI project in the framework of CEA-SRC collaboration of R\&D for the ASTRID reactor.

Furthermore, C.-M. A. is grateful for the resources provided by CEA to perform the experimental work, the scientists and engineers that taught him how to use them and aided him in metallographic studeis: Sylvie Chatain for teaching him how to calibrate and use the DTA apparatus. Kevin Ginestar for teaching how to prepare samples and use the SEM. Christophe Bonnet for aiding with sample preparation for XRD. Dominique Gosset and Justine Roubaud for performing XRD measurements and performing the initial analysis of sample FT55_X. He also thanks Prof. Malin Selleby for supervision and oversight during the work at $\mathrm{KTH}$, and his colleagues at CEA and KTH for all the advice provided for the analysis of microstructures.

Finally, C.-M. wishes to thank Professor Herbert Ipser for discussions regarding the peculiarities of the Fe-Te system, and especially for personally lending him a copy of his thesis. 


\section{Bibliography}

[1] M. G. Adamson och E. A. Aitken, "Chemical thermodynamics of Cs and Te fission product interactions in irradiated LMFBR Mixed-Oxide Fuel pins," Journal of Nuclear Materials, vol. 130, pp. 375-392, 1985.

[2] M. Naganuma, S. Koyama, T. Asaga, J. Noirot, D. Lespiaux, J. Rouault, G. Crittenden och C. Brown, "High burnup irradiation performance of annylar fuel pins irradiated in fast reactor PFR," i International symposium on MOX Fuel Cycle Technologies for Medium and Long Term Deployment, Vienna (Austria), 1999.

[3] M. Boidron, F. Boussard, J. P. Piron, J. L. Ratier och M. Tourasse, "Fast neutron reactors claddings corrosion," i 12th Scandinavian Corrosion Congress \& EUROCORR '92, Espoo, Finland, 31 May-4 June 1992, Espoo, Finland, 1992.

[4] B. Saha, R. Viswanathan, M. Saib Baba och C. K. Mathews, "Thermochemistry and phase relationships in $\mathrm{M}-\mathrm{Te}(\mathrm{M}=\mathrm{Fe}, \mathrm{Cr}$ and $\mathrm{Ni}$ ) systems of relevance to fuel-clad interactions in fast breeder nuclear reactors - a high-temperature mass spectrometric study," High TemperaturesHigh Pressures, vol. 20, pp. 47-58, 1988.

[5] C. K. Mathews, "Thermochemistry of transition metal tellurides of interest in nuclear technology," Journal of Nuclear Materials, vol. 201, pp. 99-107, 1993.

[6] M. Sai Baba, R. Viswanathan och C. K. Mathews, "Thermodynamic and Phase Diagram Studies on Metal-Tellurium Systems Employing Knudsen Effusion Mass Spectrometry," Rapid communications in mass spectrometry, vol. 10, pp. 691-698, 1996.

[7] R. J. Pulham och M. W. Richards, "Chemical reactions of caesium, tellurium and oxygen with fast breeder reactor cladding alloys. Part I - The corrosion by tellurium," Journal of Nuclear Materials, vol. 171, pp. 319-326, 1990.

[8] R. J. Pulham och M. W. Richards, "Chemical reactions of caesium, tellurium and oxygen with fast breeder reactor cladding alloys. Part II - The corrosion by caesium-oxygen mixtures," Journal of Nuclear Materials, vol. 172, pp. 47-53, 1990.

[9] R. J. Pulham och M. W. Richards, "Chemical reactions of caesium, tellurium and oxygen with fast breeder reactor cladding alloys. Part III - The effect of oxygen potential on the corrosion by caesium-tellurium mixtures," Journal of Nuclear Materials, vol. 172, pp. 206-219, 1990.

[10] R. J. Pulham och M. W. Richards, "Chemical reactions of caesium, tellurium and oxygen with fast breeder reactor cladding alloys. Part IV - The corrosion of ferritic steels," Journal of Nuclear Materials, vol. 172, pp. 304-313, 1990.

[11] R. J. Pulham och M. W. Richards, "The effect of gaseous Cs-Te mixtures on nickel," Journal of Nuclear Materials, vol. 210, pp. 30-33, 1994.

[12] F. Grønvold, H. Haraldsen och J. Vihovde, "Phase and Structural Relations in the System Iron Tellurium," Acta Chemica Scandinavica, vol. 8, pp. 1927-1942, 1954.

[13] E. Røst och S. Webjørnsen, "A High Temperature Iron Telluride with Rhobohedral Structure," 
Acta Chemica Scandinavica A, vol. 28, nr 3, pp. 361-362, 1974.

[14] S. Chiba, "The Magnetic Properties and Phase Diagram of Iron Tellurium System," Journal of the Physical Society of Japan, vol. 10, nr 10, pp. 837-842, 1955.

[15] J. P. Llewellyn och T. Smith, "The Magnetic Susceptibility of Iron Ditelluride: I," Proceedings of the Physical Society of London, vol. 74, p. 65, 1959.

[16] V. A. Geiderikh, Y. I. Gerasimov och A. V. Nikol'skaya, "Thermodynamic Properties of IronTellurium Alloys in the Solid State," (TR) Proceedings of the Academy of Sciences of the USSR. Physical Chemistry section., vol. 137, pp. 394-351, 1961.

[17] N. K. Abrikosov, K. A. Dyul'dina och V. V. Zhdanova, "Iron-Tellurium System," Khal'kogenidy, vol. 2, pp. 98-114, 1970.

[18] G. Brostigen och A. Kjekshus, "Compounds with the Marcasite Type Crystal Structure V. The crystal structure of FeS2, FeTe2 and CoTe2," Acta Chemica Scandinavica, vol. 24, nr 6, pp. 19251940, 1970.

[19] H. Ipser, K. L. Komarek och H. Mikler, "Transition Metal-Chalcogen Systems, V.: The ironTellurium Phase Diagram," Monatshefte für Chemie, vol. 105, pp. 1322-1334, 1974.

[20] G. Chattopadhyay och S. R. Bharadwaj, Evaluated phase diagrams of binary metal-tellurium systems of the D-block transition elements, Bombay: Bhabha Atomic Research Center, Water Chemistry Division, 1989.

[21] G. S. Mann och L. H. Van Vlack, "Fe1.2Te-MnTe Phase Relationships in the Presence of Excess Iron," Metallurgical Transactions B, vol. 8B, pp. 53-57, 1977.

[22] H. Okamoto och L. E. Tanner, "The Fe-Te (Iron-Tellurium) System," Bulletin of Alloy Phase Diagrams, vol. 11, nr 4, pp. 371-376, 1990.

[23] I. Oftedal, "X-Ray Investigation of Manganese Selenide, Iron Telluride, Nickel-Zinc, and PlatinumZinc," Zeitschrift für Physikalische Chemie, vol. 132, nr 3-4, pp. 208-216, 1928.

[24] S. Tengnér, "Diselenides and Ditellurides of Iron, Cobalt and Nickel," Zeitschrift für anorganische und allgemeine Chemie, vol. 239, pp. 126-132, 1938.

[25] R. M. Thompson, "Frohbergite, FeTe2: A New Member of the Marcasite Group," University of Toronto Studies, Geological Series, vol. 51, pp. 35-40, 1946.

[26] A. T. Howe, P. Coffin och B. E. F. Fender, "57Fe Mössbauer diffusional line-broadening and neutron diffraction studies of Fe1.33Te2," Journal of Physics C: Solid State Physics, vol. 9, pp. L61-L64, 1976.

[27] K. V. Reddy och S. C. Chetty, "Mössbauer Studies on the Fe-Te System," Physica Status Solidi (a), vol. 37, p. 687, 1976.

[28] P. Coffin, A. J. Jacobson och B. E. F. Fender, "The observation of an order-disorder transition in the ni-Te system by neutron diffraction," Journal of Physics C: Solid State Physics, vol. 7, pp. 2781-2790, 1974. 
[29] L. Norén, V. W. R. L. Ting och G. Van Tendeloo, "An Electron and X-Ray Diffraction Investigation of Ni1+xTe2 and Ni1+xSe2 Cdl2/NiAs Type Solid Solution Phases," Journal of Solid State Chemistry, vol. 161, pp. 266-273, 2001.

[30] H. Ipser, K. L. Komarek och R. Krachler, "Nonstoichiometry and the NiAs structure," High Temperature Materials Chemistry, pp. 101-110, 1993.

[31] J. Leciejewicz, "A Neutron Diffraction Study of Magnetic Ordering in Iron Telluride," Acta Chemica Scandinavica, vol. 17, pp. 2593-2599, 1963.

[32] D. Fruchart, P. Convert, P. Wolfers, R. Madar, J. P. Senateur och R. Fruchart, "Structure antiferromagnetique de Fe1.125Te accompagnee d'une deformation monoclinique," Materials Research Bulletin, vol. 10, pp. 169-174, 1975.

[33] A. L. N. Stevels, (Thesis) Phase Transitions in Nickel and Copper Selenides and Tellurides, Groningen: University of Groningen, 1969.

[34] G. Åkesson och E. Røst, "The Crystal Structure of Fe.28Ni.28Te.44," Acta Chemica Scandinavica, vol. 27, pp. 79-84, 1973.

[35] M. Chevreton, (Thesis) Etude structurale des séléniures et tellurures de métaux de transition, en particulier du chrome, Lyon: La Faculté des Sciences de I'Université de Lyon, 1964.

[36] J. B. Ward och V. H. McCann, "On the 57Fe Mössbauer spectra of FeTe and Fe2Te3," Journal of Physics C: Solid State Physics, vol. 12, pp. 873-879, 1979.

[37] T. A. Bither, C. T. Prewitt, J. L. Gillson, P. E. Bierstedt, R. B. Flippen och H. S. Young, "New transition metal dichalkogenides formed at high pressure," Solid State Communications, vol. 4, pp. 533-535, 1966.

[38] C. Adenis, V. Langer och O. Lindqvist, "Reinvestigation of the Structure of Tellurium," Acta Crystallographica, vol. C45, pp. 941-942, 1989.

[39] W. J. Boettinger, U. R. Kattner, K.-W. Moon och J. H. Perepezko, "DTA and Heat-Flux DSC Measurements of Alloy Melting and Freezing," i Methods for Phase Diagram Determination, J. Zhao, Red., Oxford, Elsevier , 2007, pp. 151-221.

[40] L. Lutterotti, "Total pattern fitting for the combined size-strain-stress-texture determination in thin film diffraction," Nuclear Inst. and Methods in Physics Research, B, vol. 268, pp. 334-340, 2010.

[41] K. Lutterotti, M. Bortolotti, G. Ischia, I. Lonardelli och H.-R. Wenk, "Rietveld texture analysis from diffraction images," Z. Kristalloggr., Suppl., vol. 26, pp. 125-130, 2007.

[42] T. H. De Keijser, J. I. Langford, E. J. Mittemeijer och A. B. P. Vogels, "Use of the Voigt function in a single-line method for the analysis of X-ray diffraction line broadening," Journal of Applied Crystallography, vol. 15, pp. 308-314, 1982.

[43] A. Lebail, "Whole Powder Pattern Decomposition Methods and Applications: A Retrospection," Powder Diffraction, vol. 20, nr 4, pp. 316-326, 2005. 
[44] B. P. Burton och A. K. Singh, "Prediction of entropy stabilized incommensurate phases in the system MoS2-MoTe2," Journal of Applied Physics, vol. 120, p. 155101, 2016.

[45] J. N. Coleman, M. Latoya, A. O'Neill, S. D. bergin, P. J. King, U. Khan, K. Young, A. Gaucher, S. De, R. J. Smith, I. V. Shvets, S. K. Arora, G. Stanton, H.-Y. Kim, K. Lee, G. T. Kim, G. S. Duesberg, T. Hallam, J. J. Boland, J. J. Wang, J. F. Donegan, J. C. Grunlan, G. Moriarty, A. Shmeliov, R. J. Nicholls, J. M. Perkins, E. M. Grieveson, K. Theuwissen, D. W. McComb, P. D. Nellist och V. Nicolosi, "Two-Dimensional Nanosheets Produced by Liquid Exfoliation of Layered Materials," Science, vol. 331, nr 6017, pp. 568-571, 2011.

[46] K. D. Oyler, X. S. I. T. Ke, P. Schiffer och r. E. Schaak, "Chemical Synthesis of Two-Dimensional iron Chalcogenide Nanosheets: FeSe, FeTe, $\mathrm{Fe}(\mathrm{Se}, \mathrm{Te})$, and FeTe2," Chemistry of Materials, vol. 21, pp. 3655-3661, 2009. 
Appendix

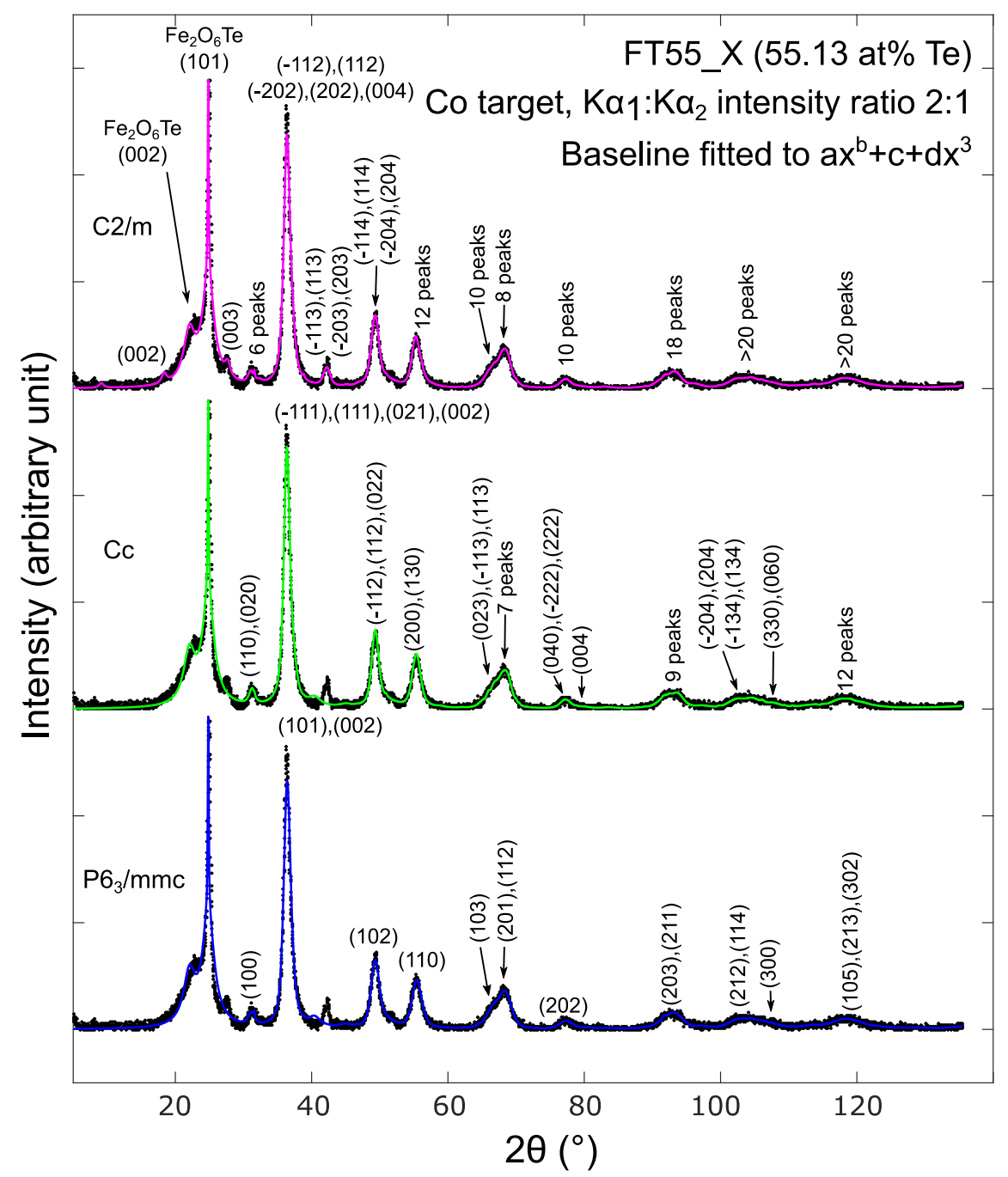

Figure A1: Comparison of rietveld refinement of space groups $\mathrm{C2} / \mathrm{m}, \mathrm{Cc}$ and $\mathrm{P} 63 / \mathrm{mmc}$ on the XRD powder pattern of FT55_X.

Table A1: Fractional atomic coordinates of $\delta$ phase of space group $C 2 / \mathrm{m}: b 1$ derived from rietveld refinement of sample FT55_X and structure relaxation with DFT computations (Part II: Thermodynamic Modelling). *: Could not be refined with the given XRD pattern. Calculated to correspond to approximately 58 at\% Te.

\begin{tabular}{|c|c|c|c|c|c|c|c|}
\hline \multicolumn{2}{|c|}{ Lattice parameters [Å] } & & & & & & \\
\hline$a$ & 6.702 & & & & & & \\
\hline$b$ & 3.856 & & & & & & \\
\hline$c$ & 11.228 & & & & & & \\
\hline$\beta$ & $90.65^{\circ}$ & & & & & & \\
\hline \multicolumn{8}{|c|}{ Fractional atomic coordinates } \\
\hline atom & $x$ & $y$ & $z$ & $B$ & Occupation & Wyckoff & Symmetry \\
\hline $\mathrm{Fe} 1$ & 0.00517 & 0 & 0.23777 & 2 & 1 & $4 i$ & $\mathrm{~m}$ \\
\hline $\mathrm{Fe} 2$ & 0 & 0 & 0 & 2 & $0.9 *$ & $2 a$ & $2 / m$ \\
\hline Te1 & 0.34112 & 0 & 0.36366 & 1 & 1 & $4 i$ & $\mathrm{~m}$ \\
\hline $\mathrm{Te} 2$ & 0.33025 & 0 & 0.87855 & 1 & 1 & $4 i$ & $\mathrm{~m}$ \\
\hline
\end{tabular}

